\title{
Experimental quantification of contact freezing in an electrodynamic balance
}

\author{
N. Hoffmann, A. Kiselev, D. Rzesanke, D. Duft, and T. Leisner \\ Karlsruhe Institute of Technology, Mailbox 3640, 76021 Karlsruhe, Germany \\ Correspondence to: N. Hoffmann (nadine.hoffmann@kit.edu)
}

Received: 14 March 2013 - Published in Atmos. Meas. Tech. Discuss.: 10 April 2013

Revised: 1 August 2013 - Accepted: 2 August 2013 - Published: 12 September 2013

\begin{abstract}
Heterogeneous nucleation of ice in a supercooled water droplet induced by external contact with a dry aerosol particle has long been known to be more effective than freezing induced by the same nucleus immersed in the droplet. However, the experimental quantification of contact freezing is challenging. Here we report an experimental method to determine the temperature-dependent ice nucleation probability of size-selected aerosol particles. The method is based on the suspension of supercooled charged water droplets in a laminar flow of air containing aerosol particles as contact freezing nuclei. The rate of droplet-particle collisions is calculated numerically with account for Coulomb attraction, drag force and induced dipole interaction between charged droplet and aerosol particles. The calculation is verified by direct counting of aerosol particles collected by a levitated droplet. By repeating the experiment on individual droplets for a sufficient number of times, we are able to reproduce the statistical freezing behavior of a large ensemble of supercooled droplets and measure the average rate of freezing events. The freezing rate is equal to the product of the droplet-particle collision rate and the probability of freezing on a single contact, the latter being a function of temperature, size and composition of the contact ice nuclei. Based on these observations, we show that for the types of particles investigated so far, contact freezing is the dominating freezing mechanism on the timescale of our experiment.
\end{abstract}

\section{Introduction}

Clouds have a considerable effect on the Earth's climate (Solomon et al., 2007). One of the most uncertain aspects in their formation, persistence, and ultimate dissipa- tion is the role played by aerosols (Levin and Cotton, 2009). Whereas some of the interaction processes, for example nucleation and condensational growth of cloud droplets on the aerosol particles, are quite well characterized, ice formation in mixed-phase clouds (MPC), and especially the potential role of contact freezing, is much less understood. MPCs containing liquid droplets and ice crystals cover about $15 \%$ of the globe, with the highest occurrence in midlatitudes and over the polar oceans (Welti et al., 2012). Contact freezing is one of four heterogeneous ice formation mechanisms responsible for glaciation of such clouds, the other three being condensation, immersion, and deposition freezing. It occurs when an aerosol particle makes contact with a supercooled cloud droplet and causes its freezing (Vali, 1985). Contact freezing might eventually explain the discrepancy between the measured number of ice nuclei (IN) and observed number concentration of ice crystals in a cloud (Avramov et al., 2011; Fridlind et al., 2007). Experimental findings suggest that contact freezing efficiency (i.e., the probability of a supercooled droplet freezing on a single contact with the IN) is a function of the temperature of the supercooled droplet and the size of the contacting particle, but the comprehensive characterization of potential contact ice nuclei in the relevant temperature range is still missing (Fan et al., 2009). Currently, no theory exists that would allow for even qualitative prediction of the IN efficiency (in any freezing mode) given the chemical structure and morphology of the IN particle. Although several studies (see Durant and Shaw, 2005; Fornea et al., 2009; Fukuta, 1975), and the recent review paper of Ladino (2013) consistently reported contact freezing taking place at temperatures that were a few degrees higher than the immersion freezing initiated by the same IN, no generally accepted explanation of this phenomenon exists up to 
this day. In particular, it is not known whether the enhancement is caused by some kind of pre-activation of the IN particle shortly before the contact with the supercooled droplet (Cooper, 1974), or by the facilitation of ice nucleation in the surface layer of a water droplet (Djikaev et al., 2002).

Even if not understood, the characterization of the atmospheric contact ice nuclei over the wide temperature range is urgently needed for implementation into the cloud models (Phillips et al., 2008). The laboratory experiments on the contact freezing of supercooled water droplets have been following two different approaches. Within the first approach, as reported, for example, from the experiments performed by (Fornea et al., 2009) and (Shaw et al., 2005), a substratesupported supercooled microdroplet was contacted repeatedly by an individual particle serving as a contact IN, and the freezing temperature was registered. These types of experiments have revealed a higher freezing temperature than compared to the case when the same particle was completely immersed into the droplet prior to the cooling. The details of the droplet-IN interaction (depth of particle penetration and morphology of the submersed part of the particle) are not known in this case and only characteristic freezing temperatures can be recorded. However, the results may vary depending on the cooling rate and on the way the cooling of the substrate and the environmental chamber is realized (Gurganus et al., 2011), and therefore are hardly suitable for parameterization.

The second approach relies on the statistical evaluation of the freezing rate when an individual droplet or an ensemble of supercooled droplets interacts with the system of aerosol particles (DeMott, 1995; Diehl et al., 2002; Ladino et al., 2011a; Levin and Yankofsky, 1983; Svensson et al., 2009; Bunker et al., 2012). In this case the total rate of freezing events is measured, and the ice nucleating efficiency can be estimated if the collision rate is known independently or can be estimated. The rate of collision events is usually evaluated indirectly either by analyzing the droplet residuals Bunker et al. (2012) or calculated numerically if the number concentration of aerosol particles and the interaction time is known (Svensson et al., 2009). Whatever the method, the accuracy of the collision rate determines the uncertainty of the freezing efficiency obtained in the experiment. Theoretical calculation of collection efficiency of a droplet in a cloud environment has been the subject of very intensive studies driven by the necessity to explain both warm and cold (i.e., involving ice phase) precipitation in a convective cloud. With respect to the contact freezing experiments, the attempts to calculate the collection efficiencies have been undertaken for the droplet-aerosol system dominated by Brownian diffusion (DeMott et al., 1983), with account for phoretic forces (see Ladino et al., 2011b, and references therein), and for the situation where either droplets or aerosol particles were strongly charged (Tinsley, 2008). In all these studies the aerosol particles were kept spherical and monodisperse.
To this day, however, neither of the approaches has been able to provide an answer to the fundamental question of what microphysical features of the particle-droplet system are responsible for the observed enhanced ice nucleation probability in the contact mode.

In the following we present a method of measuring the contact freezing efficiency of mineral dust particles colliding with a supercooled water droplet suspended in an electrodynamic balance (EDB). We show that the rate of collection of aerosol particles by a strongly charged droplet can be calculated with high accuracy taking into account various electrostatic interactions. We also show how the calculated collection efficiency can be verified independently, and demonstrate the good agreement between the predicted and measured values. Finally, we present exemplary data for contact freezing induced by mobility-selected particles of two different mineral dusts (kaolinite and hematite) and show that contact freezing is the dominating freezing mechanism on the timescales of the experiment.

It is hardly possible to compare our results with those of other authors, because the only possibility to characterize the probability of freezing on a single collision event is to treat it separately from the rate of particle-droplet collisions. As it has been recently shown in the review article of Ladino (2013), it was rarely done in the previous studies, where either the rate of the collisions or size of the ice nucleating particles were unknown, and only freezing onset temperature values were reported.

\section{Experimental}

\subsection{Aerosol generation}

As a proxy for typical mineral dust we have chosen kaolinite (product name KGa-1b), obtained from the Source Clays Repository of The Clay Minerals Society (CMS, located at Purdue University, West Lafayette, Indiana, USA), and cubic hematite $\left(\mathrm{Fe}_{2} \mathrm{O}_{3}\right)$, synthesized in our laboratory. Kaolinite KGa-1b is a well-crystallized, 1:1 layered diocathedral phyllosilicate (Giese and Oss, 2002) of the kaolin-serpentine group (the other polymorphs of kaolinite are the less common dickite, nacrite, and halloysite; see King, 2009). It is essentially an aluminum silicate whose structural unit is described by the chemical formula $\mathrm{Al}_{2} \mathrm{Si}_{2} \mathrm{O}_{5}(\mathrm{OH})_{4}$. Crystals of kaolinite have the form of pseudo-hexagonal plates with the average width of 0.2 to $0.6 \mu \mathrm{m}$, reflecting the internal arrangement of tetrahedraloctahedral building units (Fig. 1). According to CMS Source Clay Physical/Chemical Data and as confirmed by our own microprobe energy-dispersive X-ray (EDX) analysis, KGa- $1 \mathrm{~b}$ consists of more than $95 \mathrm{w} \%$ kaolinite, although anatase $\left(\mathrm{TiO}_{2}\right), \mathrm{Fe}$ oxides, quartz, and micas are observed in trace abundances (Pruett and Webb, 1993). 


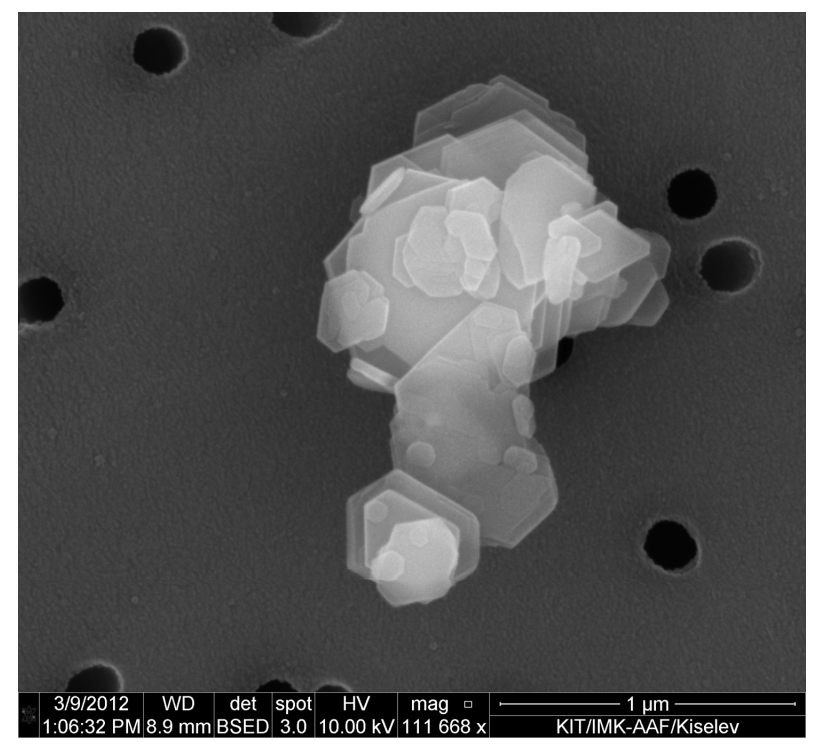

Fig. 1. SEM image of the typical agglomerate structure of a kaolinite $\mathrm{KGa}-1 \mathrm{~b}$ particle on a nuclepore filter.

Pseudo-cubic hematite particles were synthesized by hydrolysis of ferric chloride $\left(\mathrm{FeCl}_{3}\right)$ solutions in $\mathrm{NaOH}$ according to the gel-sol method $\left(54 \mathrm{~g} \mathrm{FeCl}_{3}, 21.6 \mathrm{~g} \mathrm{NaOH}\right.$ for particles with a side length of $900 \mathrm{~nm}$, and $54 \mathrm{~g} \mathrm{FeCl}_{3}, 22.8 \mathrm{~g}$ $\mathrm{NaOH}$ for particles with a side length of $300 \mathrm{~nm}$ ) described in Sugimoto et al. (1993), Kandori et al. (1992), and Sugimoto and Sakata (1992). The hematite particles were produced either in the form of suspensions in deionized water (NANOpure ${ }^{\circledR}$ Infinity Base Unit, Barnstead-Thermolyne Corporation) or freeze dried yielding the powder form. The particles have a rounded cubic shape with a side length of about $900 \mathrm{~nm}$ (Fig. 2). The shape and average size of the hematite particles in a suspension were checked prior to aerosol dispersion in the scanning electron microscope (SEM) (ESEM FEI Quanta 650 FEG).

The aerosol generation of kaolinite and hematite in a powder form was realized in a fluidized bed generator (FBG, TSI 3400A), which was operated with a dry flow of synthetic air (20 sL $\mathrm{min}^{-1}$, dew point temperature $213 \mathrm{~K}$ ). To narrow down the size range of the generated kaolinite particles, the aerosol flow was sent through a multi-orifice rotating stage cascade impactor (HAUKE, LPI-ROT 25/0018), operated with five impactor stages characterized by cut-off diameters of $2 \mu \mathrm{m}$. A fraction of the aerosol flow $\left(0.3 \mathrm{sL} \mathrm{min}^{-1}\right)$ is diverted into the differential mobility analyzer (DMA, TSI 3080) to select the particles with a desired mobility diameter. To ensure a low humidity of the sample flow, with a frost point temperature below the temperature in the EDB to avoid ice nucleation on the electrodes, an additional diffusion dryer was installed into the sheath flow loop of the DMA.

To generate hematite particles from a suspension, we used the compressed air liquid atomizer (TSI 3076) operated with

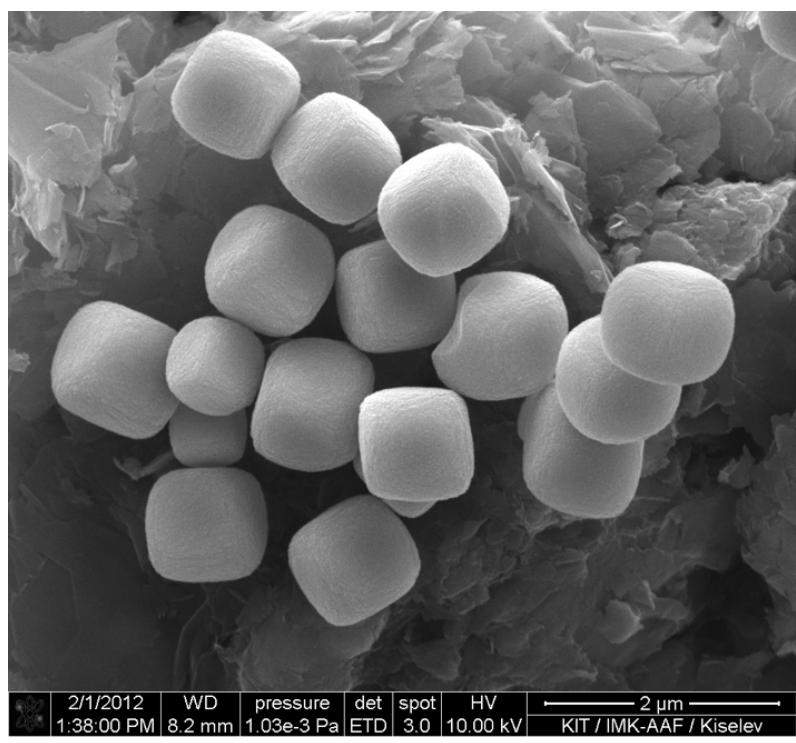

Fig. 2. SEM image of hematite particles on graphite.

$3 \mathrm{sL} \mathrm{min}^{-1}$ flow of air. The aerosol flow was then dried in the diffusion dryer and part of it $\left(0.3 \mathrm{sL} \mathrm{min}^{-1}\right)$ was directed into the DMA, which was set either to 300 or $970 \mathrm{~nm}$ mobility diameter and operated at $1: 5$ sample-to-sheath flow ratio.

Out of the DMA, the gas flow containing aerosol particles (polystyrene latex microspheres (PSL, DUKE Scientific), kaolinite, or hematite) was passed through the precooler and electrostatic precipitator and delivered into the EDB. Downstream of the EDB the particles were continuously counted by an ultrafine condensation particle counter (UCPC, TSI 3776).

For the SEM analysis the dispersed aerosol particles were collected onto a $47 \mathrm{~mm}$ Nuclepore ${ }^{\circledR}$ filter (Whatman Nuclepore track-etched membranes, $0.2 \mu \mathrm{m}$ pore size) placed into a sample holder that was installed downstream of the DMA. A section of a loaded filter was cut out, sputter-coated with a platinum layer of $1 \mathrm{~nm}$ thickness, and transferred into the SEM for imaging. The images of the individual particles have been analyzed using the open source image analysis software ImageJ (http://rsbweb.nih.gov/ij/).

\subsection{Experimental setup}

The experimental setup (Fig. 3) was built around an electrodynamic balance (EDB) of the classical hyperboloidal type (Paul and Raether, 1955; Wuerker et al., 1959). The EDB allows for contact-free storage of a charged droplet, and is described in detail in Rzesanke et al. (2012). The setup has been modified and connected to an aerosol generation system to provide a vertical laminar flow of aerosol-laden air around the suspended supercooled droplet. The horizontally mounted piezoelectric injector (GeSIM model A010006 SPIP, cylindrical housing) is used to inject individual droplets of water in the diameter range from 80 to $100 \mu \mathrm{m}$ 


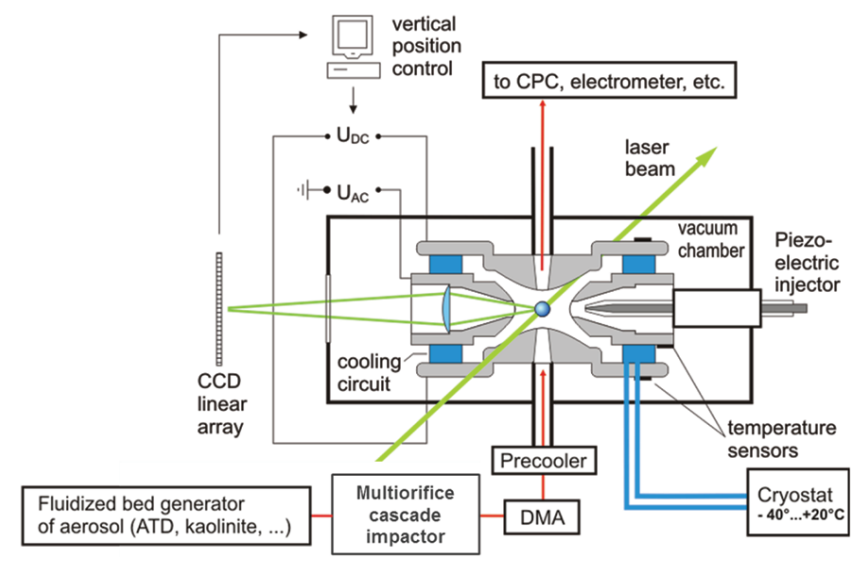

Fig. 3. Experimental setup.

into the EDB. The actual droplet size is determined by comparing the measured intensity distribution of scattered light with the phase function calculated with Mie theory (Bohren and Huffman, 2004). The droplet is charged inductively to a value of approximately $1.6 \mathrm{pC}$ during creation. The temperature of the EDB body can be controlled in the range from 230 to $300 \mathrm{~K}$ with an accuracy of $\pm 0.1 \mathrm{~K}$, allowing for droplet supercooling down to the temperature of homogeneous freezing (at about $236.5 \mathrm{~K}$ ). The temperature within the EDB is continuously monitored with temperature sensors (Pt100) located on each of the three electrodes. For the experiment described in this paper the flow from the aerosol generation system $\left(0.3 \mathrm{sL} \mathrm{min}^{-1}\right)$ was connected to the bottom inlet of the EDB, as shown in Fig. 3. To provide the possibility to remove the aerosol particles from the flow without disturbing the flow in the trap, we installed an electrostatic precipitator (EP) in front of the trap, which consists of two coaxial metal cylinders with the aerosol flowing in the gap between the cylinder walls. One of the cylinders is connected to a highvoltage switch, capable of producing a radial electric field of $2 \mathrm{kV} \mathrm{mm}^{-1}$. When actuated, all charged particles will precipitate onto the electrodes, regardless of their polarity. In order to establish a well-defined droplet temperature, the aerosol flow was preconditioned to the trap temperature in the precooler just before entering the trap. Great care has been taken to avoid turbulence in the trap. The laminarity of the flow in all points within the EDB was ensured by reducing the flow rate far below the Reynolds number values characteristic for turbulent conditions. The computational fluid dynamics (CFD) simulations with the software package ANSYS CFX 13.0 have been carried out to confirm the flow laminarity.

\subsection{Experimental sequence}

The injection of the droplet, the registration of a freezing event, and the ejection of the droplet are automated as described in Rzesanke et al. (2012). At the beginning of each cycle a water droplet is injected into the EDB, and its corre- sponding light-scattering pattern is recorded. If the droplet freezes during the preset maximum observation time, the time of freezing is registered and the frozen droplet is ejected. The freezing is detected by the strong enhancement of scattered light on the linear CCD array, which is used for the vertical droplet position control. The experimental cycle is repeated until the desired number of droplets is reached (typically 100-200 droplets were investigated in each experiment).

\subsection{Determination of the collection efficiency}

The ability to determine the rate of collisions is crucial for determination of the contact freezing efficiency. Therefore, we verified the calculated collision rate experimentally by ejecting a droplet from the EDB and collecting it on a clean silicon substrate after it had been exposed to the aerosol flow for a well-defined period of time. Prior to this process the aerosol particles are removed from the flow by the electrostatic precipitator in order to avoid that the particles are collected by the droplet during ejection, when the flow conditions are poorly determined. A metal rod with a small $(2 \mathrm{~mm} \times 2 \mathrm{~mm}$ ) silicon wafer glued to its end is lowered down into the central part of the EDB through the air-tight socket plug. Then the DC voltage across the EDB is changed so that the droplet is shifted towards the silicon wafer out of the stable levitation range. From there it is aerodynamically accelerated by the sample flow towards the wafer and hits its surface. The rod is then raised into the warm part of the outlet connector and kept in this position until the droplet has completely evaporated and the temperature of the wafer has increased above the dew point temperature of the ambient air. Then the wafer is transferred onto a sample holder of a scanning electron microscope (SEM), where the residual aerosol particles are counted and analyzed. To analyze frozen droplets in the same manner, an additional "collecting droplet" was placed in the center of the silicon wafer to avoid the bouncing of the ice crystal off the silicon surface. To facilitate the search of the submicrometer residual particles in the SEM, the "collecting droplet" has been doped with PSL particles (nominal diameter $200 \mathrm{~nm}$ ). Due to their spherical shape, the PSL particles are easily recognizable in the SEM and help in visualizing the boundary of the evaporated droplet. At the same time, the small PSL particles do not obscure the larger mineral dust particles.

\section{Data evaluation}

\subsection{Statistical description of a freezing experiment}

In the discussion that follows, we assume that the contact freezing is different from immersion freezing in the sense that contact freezing occurs immediately at the moment of contact between the supercooled droplet and the aerosol particle, whereas immersion freezing is a rate-driven process 


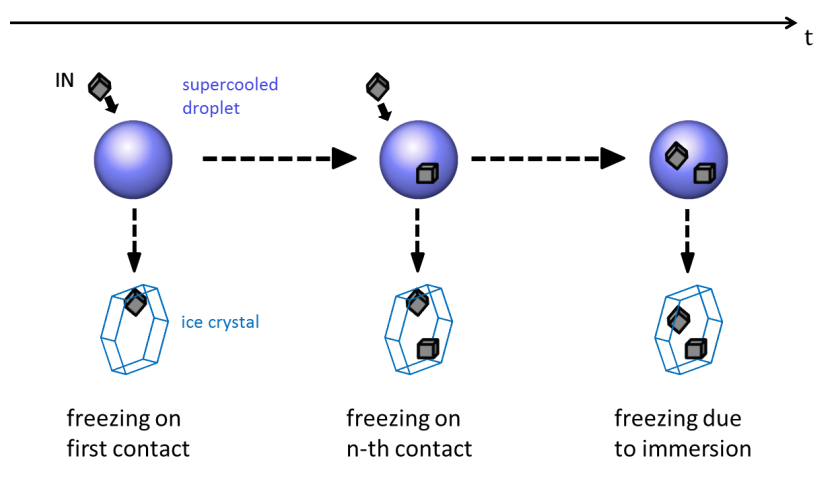

Fig. 4. Possible pathways of droplet freezing.

with the rate of ice nucleation being a function of temperature, surface area available for heterogeneous nucleation of ice, and the propensity of the substrate to ice nucleation (Pruppacher and Klett, 2004).

A supercooled droplet suspended in a flow of aerosol particles may freeze along different pathways, either via contact freezing or immersion freezing due to the previously collected particles (Fig. 4). The freezing may occur on the first contact with an ice nucleus (IN). Alternatively, the droplet may collect one or more IN without freezing and then freeze at the $n$-th contact with an IN. Finally, the droplet can collect one or more IN and freeze along the immersion freezing pathway. In the following we show how the different freezing mechanisms can be handled separately.

In a system of $N_{0}$ identical water droplets supercooled to a constant temperature $T$ and subjected to a constant rate of contacts with aerosol particles that are taken up by the droplets, freezing is a random process described by a rate equation:

$\frac{\mathrm{d} N_{\mathrm{u}}}{\mathrm{d} t}=-J_{\mathrm{tot}}(t) \cdot N_{\mathrm{u}}$

where $N_{\mathrm{u}}$ is the number of unfrozen droplets and $J_{\text {tot }}(t)$ is the total rate of freezing events.

To account for the different freezing mechanisms (Fig. 4) and assuming that droplets freeze independently, we separate the total rate of freezing into two parts - the rate of immersion freezing $J_{\mathrm{i}}(t)$ and the rate of contact freezing $J_{\mathrm{c}}$ :

$J_{\text {tot }}=J_{\mathrm{i}}+J_{\mathrm{c}}$.

According to the classical nucleation theory for heterogeneous nucleation (Pruppacher and Klett, 2004), the total rate of immersion freezing would be a product of a nucleation rate coefficient $j_{i}$, the surface of a single immersed ice nucleus $S_{\mathrm{IN}}$, and the number of particles in the droplet $n_{\mathrm{IN}}$. Assuming that all particles are identical, and taking into account that the number of particles collected by the droplet $n_{\mathrm{IN}}$ after time $t$ is the product of the collection rate $n_{\mathrm{c}}$ and time $t$, we obtain

$J_{\mathrm{i}}=S_{\mathrm{IN}} \cdot j_{\mathrm{i}} \cdot n_{\mathrm{c}} \cdot t$.

The rate of contact freezing events is given by the collection rate $n_{\mathrm{c}}$ times the probability of droplet freezing upon a single contact (in the following, contact freezing probability) $e_{\mathrm{c}}$ :

$J_{\mathrm{c}}=n_{\mathrm{c}} \cdot e_{\mathrm{c}}$.

Combining Eqs. (2), (3), and (4), substituting into Eq. (1) and integrating yields

$$
\begin{aligned}
\int_{N_{0}}^{N_{\mathrm{u}}} \frac{\mathrm{d} N_{\mathrm{u}}^{\prime}}{N_{\mathrm{u}}^{\prime}} & =-\int_{0}^{t} n_{\mathrm{c}}\left(S_{\mathrm{IN}} j_{\mathrm{i}} t^{\prime}+e_{\mathrm{c}}\right) \mathrm{d} t^{\prime}, \\
\ln \left(\frac{N_{\mathrm{u}}}{N_{0}}\right) & =-\frac{1}{2} S_{\mathrm{IN}} n_{\mathrm{c}} j_{\mathrm{i}} t^{2}-n_{\mathrm{c}} e_{\mathrm{c}} t .
\end{aligned}
$$

Equation (6) includes a quadratic time-dependent term describing the immersion freezing and the linear timedependent term describing the contact freezing. A direct implication of such a functional form is obvious: if we assume the rate of contact freezing events $J_{\mathrm{c}}$ being very small, the quadratic term (immersion freezing) will dominate the form of the function $\ln \left(N_{\mathrm{u}} / N_{0}\right)$ plotted against time ("freezing curve"), which will have a square law shape; vice versa, if contact freezing dominates, the equation simplifies to

$\ln \left(\frac{N_{\mathrm{u}}}{N_{0}}\right)=-n_{\mathrm{c}} \cdot e_{\mathrm{c}} \cdot t$,

which yields a linear dependence of $\ln \left(N_{\mathrm{u}} / N_{0}\right)$ on time. Using the expressions from Eqs. (3) and 4 the condition for the linearity of the freezing curve $J_{\mathrm{c}} \gg J_{\mathrm{i}}$ can be rewritten

$e_{\mathrm{c}} \gg \frac{1}{2} S_{\mathrm{IN}} j_{\mathrm{i}} t$.

From this follows that if we observe a linear freezing curve, the probability of contact freezing upon a single collision $e_{\mathrm{c}}$ is higher than the probability of immersion freezing after waiting the time $t_{\max }$, which in our experiment was typically set to $30 \mathrm{~s}$. The above expression, Eq. (8), also provides the basis for comparison of the contact and immersion freezing rates for atmospherically relevant types of IN and realistic collision rates: for the given rate of collisions $n_{\mathrm{c}}$ between droplets supercooled to the temperature $T_{\mathrm{S}}$ and IN with characteristic values $S_{\mathrm{IN}}, j_{\mathrm{i}}$, and $e_{\mathrm{c}}$, one can define the average time $t_{\mathrm{im}}$ after which the immersion freezing rate would start dominating the contact freezing:

$t_{\mathrm{im}}=\frac{2 e_{\mathrm{c}}}{S_{\mathrm{IN}} j_{\mathrm{i}}}$.

For the particles and conditions reported in this manuscript, the condition $t<<t_{\text {im }}$ is always fulfilled. In this case 


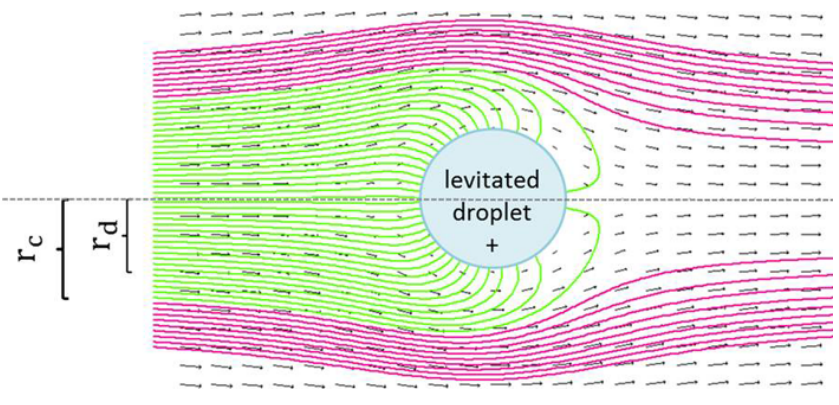

Fig. 5. Trajectories of charged aerosol particles in a laminar flow around a charged sphere. The arrows correspond to the vector field of the flow; green lines corresponds to the trajectories that lead to a collision. Temperature: $240 \mathrm{~K}$; droplet charge: $1.63 \mathrm{pC}$; particle charge: 1e; linear velocity of the flow at infinity: $0.471 \mathrm{~m} \mathrm{~s}^{-1}$

the simplified equation Eq. (7) is valid, and with the slope of the freezing curve defined as $m_{\exp }$, we have a simple expression for the contact freezing probability $e_{\mathrm{c}}$ :

$e_{\mathrm{c}}=\frac{m_{\mathrm{exp}}}{n_{\mathrm{c}}}$.

To calculate the contact freezing probability, it is necessary to know the collision rate $n_{\mathrm{c}}$. We show in the following section that, under our experimental conditions, the collision rate can be calculated theoretically and can be verified experimentally for selected cases.

\subsection{Calculation of collection efficiency}

To calculate the rate of collisions of aerosol particles with a spherical droplet in a laminar flow, one has to know the collection efficiency, which is defined as

$\eta=\frac{\pi r_{\mathrm{c}}^{2}}{\pi\left(r_{\mathrm{d}}+r_{\mathrm{p}}\right)^{2}}$.

Here $r_{\mathrm{d}}$ and $r_{\mathrm{p}}$ are the radii of the droplet and aerosol particle, respectively, and $r_{\mathrm{c}}$, measured perpendicular to the flow axis and sufficiently far upstream of the droplet, is the largest offset a particle can have from the droplet center and still be able to collide with the droplet.

The basic analytical formulation for the collection efficiency of charged aerosol particles of radius $r_{\mathrm{p}}$ and charge $q_{\mathrm{p}}$ in a laminar gas flow of velocity $v_{0}$ around an oppositely charged sphere of radius $r_{\mathrm{d}}$ and charge $q_{\mathrm{d}}$ was given by (Kraemer and Johnstone, 1955)

$\eta=\frac{C_{\mathrm{c}}\left(r_{\mathrm{p}}\right) q_{\mathrm{p}} q_{\mathrm{d}}}{6 \pi^{2} \epsilon_{0} \mu r_{\mathrm{p}} r_{\mathrm{d}}^{2} v_{0}}$,

where $\epsilon_{0}$ denotes the permittivity of free space, $\mu$ is the dynamic viscosity of the carrier gas, and $C_{\mathrm{c}}\left(r_{\mathrm{p}}\right)$ is the Cunningham slip correction factor (Allen and Raabe, 1982).

This formulation includes drag force and static Coulomb interaction only. However, several other forces have to be considered: induced dipole interaction between charged droplet and polarizable aerosol particles, the random motion of aerosol particles due to diffusion and turbulence effects, phoretic forces arising due to the temperature and water vapor density gradients around the droplet, and the repulsion forces between the individual aerosol particles. We have calculated the forces and found that the phoretic forces are two to four orders of magnitude lower than the electrostatic forces. For our experimental conditions, we can neglect all of them except for the Coulomb force and the induced dipole interaction, which becomes a major interaction force at small separation distances. Under this assumption, the force exerted by a spherical droplet onto aerosol particle is given as follows:

$\mathbf{F}=-\left(\frac{\epsilon_{\mathrm{r}}-1}{\epsilon_{\mathrm{r}}+2}\right) \frac{d_{\mathrm{p}}^{3} q_{\mathrm{d}}^{2}}{16 \pi \epsilon_{0} r_{\mathrm{dp}}^{5}} \cdot \mathbf{e}_{\mathrm{dp}}+\frac{q_{\mathrm{d}} q_{\mathrm{p}}}{4 \pi \epsilon_{0} r_{\mathrm{dp}}^{2}} \cdot \mathbf{e}_{\mathrm{dp}}+\frac{6 \pi \mu r_{\mathrm{p}}}{C_{\mathrm{c}}\left(r_{\mathrm{p}}\right)} \cdot \mathbf{w}$.

The first two terms describe the electrostatic force between the charged droplet and charged particle acting along the unit vector $\mathbf{e}_{\mathrm{dp}}$, and the third term describes the drag force aligned with the unit vector $\mathbf{w}$ of the flow-particle relative velocity. Here $r_{\mathrm{dp}}$ is the droplet-particle separation distance, and $\epsilon_{\mathrm{r}}$ is the dielectric constant of the particle material. The magnitude of $\epsilon_{\mathrm{r}}$ is not well defined for minerals used in the experiment we report here; however, the overall value of the collection efficiency is only slightly affected by the magnitude of $\epsilon_{\mathrm{r}}$. We used values of $\epsilon_{\mathrm{r}}=25$ for hematite (Carmichael, 1982) and $\epsilon_{\mathrm{r}}=5.1$ for kaolinite (Robinson, 2004).

The differential equation of particle motion in a viscous flow around the motionless droplet is then integrated numerically to obtain the particle trajectories (Fig. 5). The trajectory of special interest is the boundary trajectory, which defines the maximum offset $r_{\mathrm{c}}$ in the infinity. Once $r_{\mathrm{c}}$ is determined, the collection efficiency $\eta$ is calculated according to Eq. (11). The collision rate $n_{\mathrm{c}}$ is then given by

$n_{\mathrm{c}}=\pi r_{\mathrm{d}}^{2} \cdot N_{\mathrm{c}} \cdot v_{\mathrm{s}} \cdot \eta$,

where $N_{\mathrm{c}}$ is the particle number concentration as measured by the CPC downward from the EDB, and $v_{\mathrm{s}}$ is the volume flow rate of the sample flow through the EDB.

\section{Experimental results}

\subsection{Experimental determination of collection efficiency}

The method of $n_{\mathrm{c}}$ calculation described in the previous section is valid only for spherical and monodisperse aerosol particles. To verify the validity of the method and also to evaluate the error arising from the deviation of the aerosol from the ideality, we have compared the collection efficiencies measured experimentally as described in the Sect. 2.4 with numerical calculations. 
Table 1. Comparison of theoretical and experimental collection efficiency for PSL microspheres, kaolinite KGa-1b, and hematite particles.

\begin{tabular}{lrrrr}
\hline $\begin{array}{l}\text { Investigated } \\
\text { material }\end{array}$ & $\begin{array}{r}\text { Mobility diameter } \\
\text { set by DMA }(\mathrm{nm})\end{array}$ & $\begin{array}{r}\text { Total number of } \\
\text { investigated } \\
\text { droplets }\end{array}$ & $\begin{array}{r}\text { Calculated } \\
\text { collection } \\
\text { efficiency }\end{array}$ & $\begin{array}{r}\text { Experimental } \\
\text { collection } \\
\text { efficiency }\end{array}$ \\
\hline PSL & 440 & 7 & 0.32 & $0.17 \pm 0.16$ \\
PSL & 720 & 6 & 0.31 & $0.18 \pm 0.10$ \\
Kaolinite KGa-1b & 550 & 4 & 0.57 & $0.76 \pm 0.24$ \\
Hematite & 970 & 13 & 0.80 & $0.81 \pm 0.15$ \\
\hline
\end{tabular}

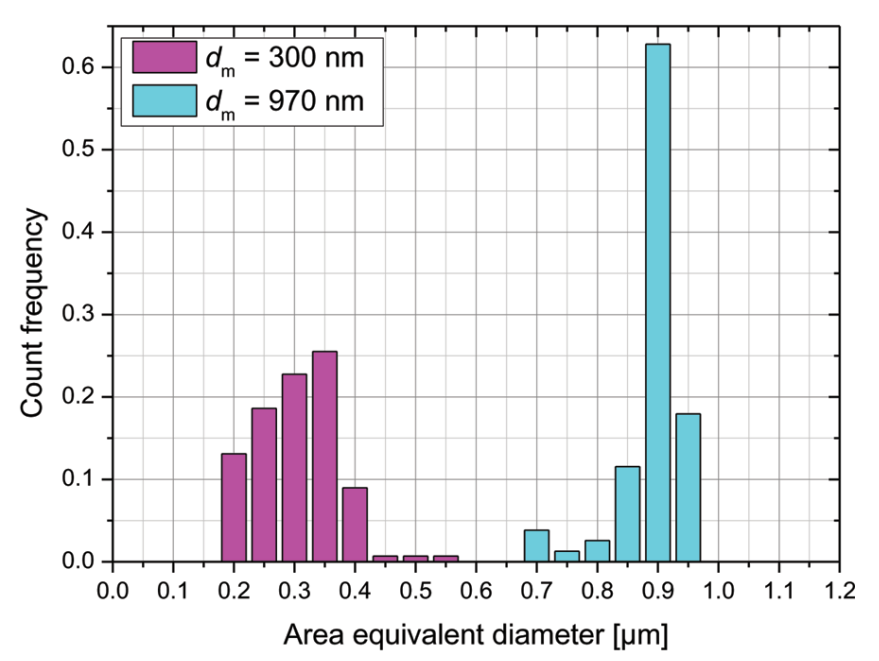

Fig. 6. Size distribution of hematite particles obtained from ESEM analysis of the projection area.

The uncertainties that have to be considered when calculating $n_{\mathrm{c}}$ are the particle size, shape, and charge. Although the aerosol particles are preselected in the DMA, and thus have the same electrical mobility, its value is a function of particle size, orientation, and charge (Seinfeld and Pandis, 1998). Therefore, depending on the shape of the size distribution of aerosol entering the DMA, a certain amount of larger particles carrying multiple charges will always penetrate the DMA. Generally, the number fraction of multiply charged particles is unknown. Furthermore, clay mineral particles have a plate agglomerate structure, and therefore their electrical mobility is a function of particle orientation with respect to the flow lines. We have examined the influence of particle shape by measuring the collection efficiencies for three different types of aerosol: polystyrene latex (PSL) microspheres, hematite cubical particles, and kaolinite KGa- $1 \mathrm{~b}$. The results of the comparison are shown in the Table 1.

The PSL particles are ideal spheres with a very narrow size distribution ( $\sigma \leq 0.05$ according to the manufacturer data sheet) and well-known material density $\rho=1.05 \mathrm{~g} \mathrm{~cm}^{-3}$, so that the best possible match between the theory and experiment could be expected. However, the examination of the footprints of water droplets in SEM revealed higher fraction of agglomerated PSL particles than what one would anticipate given the actual number concentration of PSL particles in the prepared suspension. It is possible that the agglomeration occurs on the surface of a liquid droplet during the droplet evaporation, and there is no way of distinguishing these agglomerates from the multiplets of the PSL microspheres selected by DMA. To avoid this ambiguity, we have counted all multiplets as single particles within the droplet footprint, which resulted in a strong underestimation (by more than $50 \%$ ) of the collection efficiency as compared to the expected theoretical value. It is worth noting, however, that the collection efficiency $\eta$ was found to be almost equal for both 440 and $720 \mathrm{~nm}$ PSL microspheres, in agreement with the theory.

Table 1 also shows the collection efficiency measured and calculated for kaolinite KGa-1b particles with mobility diameter $d_{\mathrm{m}}=550 \mathrm{~nm}$. In the calculation the presence of single and doubly charged particles with the same mobility has been taken into account. The fraction of particles carrying multiple charges has been evaluated from the SEM analysis of filter samples. In this case, the predicted collection efficiency underestimated the measured value by $25 \%$, which is most likely due to highly non-spherical shape of the kaolinite particles.

The collection efficiency for hematite particles with a mobility diameter of $d_{\mathrm{m}}=970 \mathrm{~nm}$ has been measured by ejecting frozen and liquid droplets. Whether the droplet was liquid or frozen during the ejection has no effect on the determination of collection efficiency, since in both cases the droplet was liquid while it was collecting particles. The difference in the ejection method is described in Sect. 2.4.

Hematite particles of this size have a very uniform shape (as shown in Fig. 2) and a narrow size distribution (see Fig. 6). In this case the experimental collection efficiency was in a very close agreement with the expected theoretical value.

The variability of the experimental collection efficiency is a result of the statistical nature of the particle collection process and the small number of investigated droplets. 


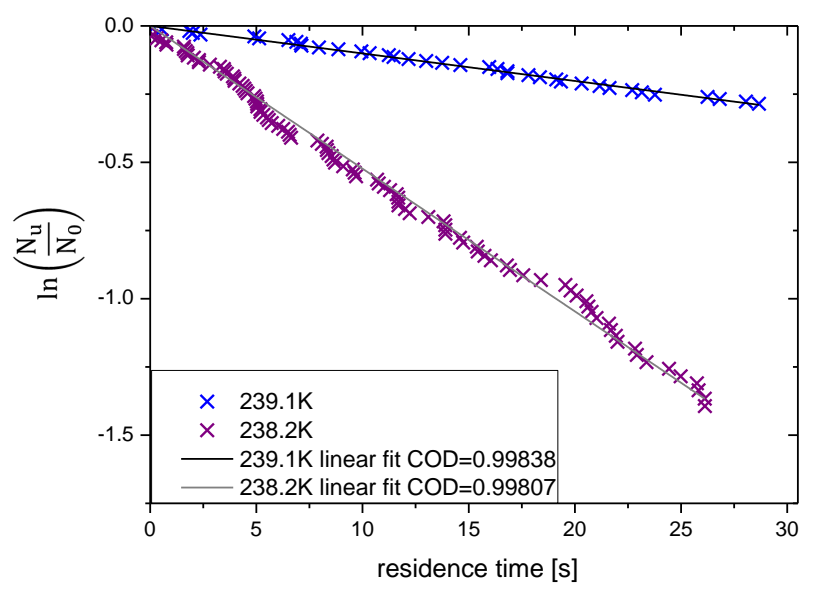

Fig. 7. Example measurements of contact freezing curves.

\subsection{Experimental determination of contact freezing probability}

We have investigated the freezing of supercooled water droplets on a contact with kaolinite particles (mobility diameter of $550 \mathrm{~nm}$ ) and with hematite particles (mobility diameter of 970 and $300 \mathrm{~nm}$ ) within the temperature range between 240.3 and $237.9 \mathrm{~K}$. An average water droplet had a diameter of about $80 \mu \mathrm{m}$ and charge of about $1.6 \mathrm{pC}$. Normally, 100-200 droplets were investigated for each temperature data point. To exclude the influence of contamination in the droplets and inside the EDB, at the beginning of each experimental sequence, the droplets were trapped with aerosol flow switched off, and no freezing was observed. The number concentration of particles was about $150 \mathrm{~cm}^{-3}$ for kaolinite $\mathrm{KGa}-1 \mathrm{~b}$ and about $300 \mathrm{~cm}^{-3}$ for both hematite samples. Figure 7 shows two typical freezing curves (in this example for kaolinite $\mathrm{KGa}-1 \mathrm{~b}$ with a mobility diameter of $550 \mathrm{~nm}$, EDB temperature set to 238.2 and $239.1 \mathrm{~K}$ ) as described in Sect. 2.3. We interpret the linearity of the freezing curve as an indication of the dominating nature of the contact freezing mechanism on the timescale of an experiment of $30 \mathrm{~s}$ (see Eq. 6 and discussion in the Sect. 3.1).

With the slope $m_{\exp }$ of the freezing curve and the calculated collection rate $n_{c}$ we can now determine the contact freezing probability (Eq. 10). Figure 8 shows the results.

The contact freezing probability $e_{\mathrm{c}}$ is a steep function of temperature. The size and composition of the mineral dust particles seems to be essential for the contact freezing probability. For the contact IN of the same composition, the larger the particle, the higher the contact freezing probability, in agreement with results reported by Hoffmann et al. (2013) for illite mineral dust particles.

Obviously kaolinite KGa- $1 \mathrm{~b}$ is a better contact IN than hematite. Freezing starts at a higher temperature, and, although the diameter is smaller, the freezing probability is

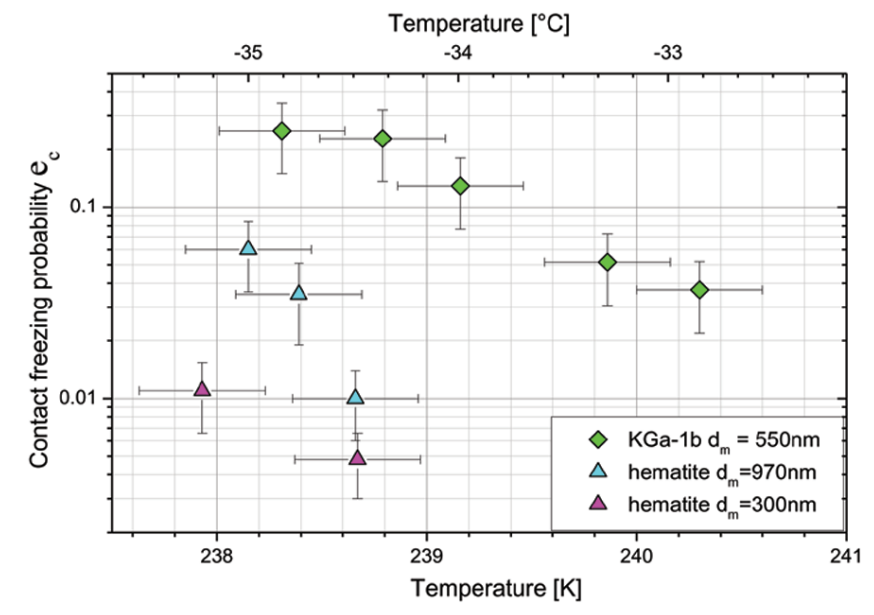

Fig. 8. Freezing probability as a function of temperature. Green diamonds represent the results from the experiment with kaolinite KGa-1b with a mobility diameter of $d_{\mathrm{m}}=550 \mathrm{~nm}$. The triangles shows the results of the experiments with hematite (blue: $d_{\mathrm{m}}=970 \mathrm{~nm}$; magenta: $d_{\mathrm{m}}=300 \mathrm{~nm}$ ).

higher than the freezing probability of hematite. Even if we underestimate the collection efficiency of kaolinite particles by about $25 \%$ (compare to Table 1), and that the value of freezing probability would decrease by about $25 \%$, it is still significantly higher than the freezing probability found for hematite of $970 \mathrm{~nm}$ mobility diameter. Of each ensemble of droplets, at least five freezing events have to be registered to ensure a minimum statistical significance of the calculated freezing rate. This condition together with the experimentally limited aerosol particle number concentration (typically on the order of $100-300 \mathrm{~cm}^{-3}$ ) sets the value of the smallest measurable contact freezing probability to approximately $1 \%$. As the contact freezing probability is a steep function of the temperature, only small temperature ranges can be investigated with this method for each aerosol type. Furthermore the contact freezing probability cannot be related unambiguously to the onset temperature (defined as a supercooling temperature at which some fraction of droplets - typically $1 \%$ - are frozen), because the fraction of frozen droplets is also a function of collision rate.

The discussion of the error bars of the collection efficiency is given in Sect. 4.1. For the calculation of the freezing probability, a variability of the slope of the freezing curve has to be taken into account. This depends on the number of investigated droplets, and in the case of our experiments, the variability is about $10 \%$.

Finally, we have to address the question of how charge may effect the measurements of freezing probability. As shown in Rzesanke et al. (2012), there is no effect of the charge on the homogeneous freezing of a supercooled droplet of pure water. However, the contact freezing is induced by an aerosol particle located on the surface of the droplet (and this is where the charge on the droplet is localized too), whereas 
homogeneous freezing is a volume-dominated process (Duft et al., 2004). Though we cannot entirely exclude the possibility of charge effect on the contact freezing probability, we see no evidence for that. On the other hand, the fact that the freezing probability exhibits temperature, IN particle material, and IN particle size dependence in line with the general pattern of heterogeneous freezing suggests that the effect of charge carried by the droplet is negligible.

\section{Conclusions and outlook}

We have built a setup to measure the contact freezing probability of supercooled water droplets colliding with aerosol particles. The method is based on the observation of individual droplets of pure water levitated in an EDB and exposed to a flow of dry aerosol particles passing through the EDB. The collection efficiency is calculated according to the method of Kraemer and Johnstone (1955), and was adapted for this experiment as described in Hoffmann et al. (2013). The experiments were conducted at temperatures from 240.3 to $237.9 \mathrm{~K}$. Here we reported first measurements of the contact freezing probability for kaolinite from the Clay Mineral Society and hematite (produced in our laboratory).

A newly developed method was described to verify the calculated collection efficiency. It is based on the collection of the levitated droplets onto a Si wafer followed by analysis of the residuals in SEM. Especially for compact-shaped hematite particles, we obtained very good agreement with the calculations.

Based on the statistical analysis of the experimental results we have shown that the contact freezing is the dominating freezing mechanism on the timescale of the experiment. This allows for us to extract, for the first time, quantitative contact freezing probabilities for various realistic aerosol particles as a function of temperature. As expected, the resulting contact freezing probabilities do depend strongly on the temperature. Compared to kaolinite, hematite was found to be a rather poor ice nucleus both in contact and in immersion mode.

A careful investigation of the size and aerosol morphology dependence on the contact freezing probability, as implicated by the results of this work, is currently being performed in our laboratory for a wider range of mineral dust and other aerosol particles.

By switching off the aerosol flow before the "contact" freezing occurs (and therefore allowing for controlled collection of particles by a liquid droplet), the same experimental setup allows for measurements of the immersion freezing of the supercooled microdroplets. Such an approach enables a direct comparison of the freezing rates induced by the same ice nuclei in contact and immersion ice nucleation mode. We will address these issue in the forthcoming publications.
Acknowledgements. The reported study was supported by the German Research Society (DFG) under contracts LE8343/2-3 and FOR 1525 INUIT. We would also like to thank Sarah Jaeger for the preparation of the hematite particles. The building of the electrostatic precipitator and LabView programming by Jens Nadolny is highly acknowledged.

The service charges for this open access publication have been covered by a Research Centre of the Helmholtz Association.

Edited by: P. Herckes

\section{References}

Allen, M. and Raabe, O.: Re-evaluation of millikan's oil drop data for the motion of small particles in air, J. Aerosol Sci., 13, 537 547, doi:10.1016/0021-8502(82)90019-2, 1982.

Avramov, A., Ackerman, A. S., Fridlind, A. M., van Diedenhoven, B., Botta, G., Aydin, K., Verlinde, J., Korolev, A. V., Strapp, J. W., McFarquhar, G. M., Jackson, R., Brooks, S. D., Glen, A., and Wolde, M.: Toward ice formation closure in Arctic mixed-phase boundary layer clouds during ISDAC, J. Geophys. Res., 116, D00T08, doi:10.1029/2011jd015910, 2011.

Bohren, C. F. and Huffman, D. R.: Absorption and Scattering of Light by Small Particles, Wiley-VCH, Weinheim, 2004.

Bunker, K. W., China, S., Mazzoleni, C., Kostinski, A., and Cantrell, W.: Measurements of ice nucleation by mineral dusts in the contact mode, Atmos. Chem. Phys. Discuss., 12, 2029120309, doi:10.5194/acpd-12-20291-2012, 2012.

Carmichael, R. S.: Handbook of Physical Properties of Rocks, CRC Press, Boca Raton, FL, United-States, 1982.

Cooper, W. A.: Possible mechanism for contact nucleation, J. Atmos. Sci., 31, 1832-1837, 1974.

DeMott, P. J.: Quantitative descriptions of ice formation mechanisms of silver iodide-type aerosols, Atmos. Res., 38, 63-99, 1995.

DeMott, P. J., Finnegan, W. G., and Grant, L. O.: An application of chemical kinetic-theory and methodology to characterize the ice nucleating properties of aerosols used for weather-modification, J. Clim. Appl. Meteorol., 22, 1190-1203, 1983.

Diehl, K., Matthias-Maser, S., Jaenicke, R., and Mitra, S. K.: The ice nucleating ability of pollen, Part 2: laboratory studies in immersion and contact freezing modes, Atmos. Res., 61, 125-133, 2002.

Djikaev, Y. S., Tabazadeh, A., Hamill, P., and Reiss, H.: Thermodynamic conditions for the surface-stimulated crystallization of atmospheric droplets, J. Phys. Chem. A, 106, 10247-10253, 2002.

Duft, D. and Leisner, T.: Laboratory evidence for volumedominated nucleation of ice in supercooled water microdroplets, Atmos. Chem. Phys., 4, 1997-2000, 2004, http://www.atmos-chem-phys.net/4/1997/2004/.

Durant, A. J. and Shaw, R. A.: Evaporation freezing by contact nucleation inside-out, Geophys. Res. Lett., 32, L20814, doi:10.1029/2005g1024175, 2005.

Fan, J., Ovtchinnikov, M., Comstock, J. M., McFarlane, S. A., and Khain, A.: Ice formation in Arctic mixed-phase clouds: insights from a 3-D cloud-resolving model with size-resolved 
aerosol and cloud microphysics, J. Geophys. Res., 114, D04205, doi;10.1029/2008jd010782, 2009.

Fornea, A. P., Brooks, S. D., Dooley, J. B., and Saha, A.: Heterogeneous freezing of ice on atmospheric aerosols containing ash, soot, and soil, J. Geophys. Res.-Atmos., 114, D13201, doi:10.1029/2009jd011958, 2009.

Fridlind, A. M., Ackerman, A. S., McFarquhar, G., Zhang, G., Poellot, M. R., DeMott, P. J., Prenni, A. J., and Heymsfield, A. J.: Ice properties of single-layer stratocumulus during the MixedPhase Arctic Cloud Experiment: 2. model results, J. Geophys. Res., 112, D24202, doi:10.1029/2007jd008646, 2007.

Fukuta, N.: Possible mechanism for contact nucleation - comment, J. Atmos. Sci., 32, 2371-2373, 1975.

Giese, R. F. and Oss, C. J. V.: Colloid and Surface Properties of Clays and Related Minerals, Surfactant Science Series, vol. 105, Marcel Dekker, Inc., New York, 2002.

Gurganus, C., Kostinski, A. B., and Shaw, R. A.: Fast imaging of freezing drops: no preference for nucleation at the contact line, J. Phys. Chem. Lett., 2, 1449-1454, 2011.

Hoffmann, N., Duft, D., Kiselev, A., and Leisner, T.: Contact freezing efficiency of mineral dust aerosols studied in an electrodynamic balance: Quantitative size and temperature dependence for illite particles, Faraday Discuss., doi:10.1039/C3FD00033H, accepted, 2013.

Kandori, K., Kawashima, Y., and Ishikawa, T.: Effects of citrate ions on the formation of monodispersed cubic hematite particles, J. Colloid Interf. Sci., 152, 284-288, doi:10.1016/00219797(92)90028-K, 1992.

King, R.: Kaolinite, Geology Today, 25, 75-78, doi:10.1111/j.13652451.2009.00711.x, 2009.

Kraemer, H. F. and Johnstone, H. F.: Collection of aerosol particles in presence of electrostatic fields, Ind. Eng. Chem., 47, 24262434, 1955.

Ladino, L. A., Stetzer, O., and Lohmann, U.: Contact freezing: a review, Atmos. Chem. Phys. Discuss., 13, 7811-7869, doi:10.5194/acpd-13-7811-2013, 2013.

Ladino, L., Stetzer, O., Hattendorf, B., Gunther, D., Croft, B., and Lohmann, U.: Experimental study of collection efficiencies between submicron aerosols and cloud droplets, J. Atmos. Sci., 68, 1853-1864, 2011a.

Ladino, L., Stetzer, O., Luond, F., Welti, A., and Lohmann, U.: Contact freezing experiments of kaolinite particles with cloud droplets, J. Geophys. Res.-Atmos., 116, D22202, doi:10.1029/2011jd015727, 2011b.

Levin, Z. and Cotton, W. R. (Eds.): Aerosol Pollution Impact on Precipitation, a Scientific Review, Springer Science and Business Media B.V. 2009, Dordrecht, Holland, 2009.

Levin, Z. and Yankofsky, S. A.: Contact versus immersion freezing of freely suspended droplets by bacterial ice nuclei, J. Clim. Appl. Meteorol., 22, 1964-1966, 1983.

Paul, W. and Raether, M.: Das elektrische Massenfilter, Z. Phys., 140, 262-273, 1955.
Phillips, V. T. J., DeMott, P. J., and Andronache, C.: An empirical parameterization of heterogeneous ice nucleation for multiple chemical species of aerosol, J. Atmos. Sci., 65, 2757-2783, 2008.

Pruett, R. J. and Webb, H. L.: Sampling and analysis of KGa-1B well-crystallized kaolin source clay, Clay. Clay Miner., 41, 514 19, 1993.

Pruppacher, H. R. and Klett, J. D.: Microphysics of Clouds and Precipitation, 2nd Edn., Kluver Academic Publishers, the Netherlands, 2004.

Robinson, D. A.: Measurement of the solid dielectric permittivity of clay minerals and granular samples using a time domain reflectometry immersion method, Vadose Zone J., 2, 705-713, 2004.

Rzesanke, D., Nadolny, J., Duft, D., Muller, R., Kiselev, A., and Leisner, T.: On the role of surface charges for homogeneous freezing of supercooled water microdroplets, Phys. Chem. Chem. Phys., 14, 9359-9363, 2012.

Seinfeld, J. H. and Pandis, S. N.: Atmospheric Chemistry and Physics, 1326 pp., John Wiley, Hoboken, NJ, 1998.

Shaw, R. A., Durant, A. J., and Mi, Y.: Heterogeneous surface crystallization observed in undercooled water, J. Phys. Chem. B, 109, 9865-9868, 2005.

Solomon, S., Qin, D., Manning, M., Chen, Z., Marquis, M., Tignor, K. A., and Miller, H. (Eds.): IPCC, 2007: Climate Change 2007: the Physical Science Basis, Contribution of Working Group I to the Fourth Assessment Report of the Intergovernmental Panel on Climate Change, Cambridge University Press, Cambridge, United Kingdom and New York, NY, USA, 2007.

Sugimoto, T. and Sakata, K.: Preparation of monodisperse pseudocubic alfa- $\mathrm{Fe}_{2} \mathrm{O}_{3}$ particles from condensed ferric hydroxide gel, J. Colloid Interf. Sci., 152, 587-590, doi:10.1016/00219797(92)90062-Q, 1992.

Sugimoto, T., Sakata, K., and Muramatsu, A.: Formation mechanism of monodisperse pseudocubic alfa- $\mathrm{Fe}_{2} \mathrm{O}_{3}$ particles from condensed ferric hydroxide gel, J. Colloid Interf. Sci., 159, 372 382, doi:10.1006/jcis.1993.1336, 1993.

Svensson, E. A., Delval, C., von Hessberg, P., Johnson, M. S., and Pettersson, J. B. C.: Freezing of water droplets colliding with kaolinite particles, Atmos. Chem. Phys., 9, 4295-4300, doi:10.5194/acp-9-4295-2009, 2009.

Tinsley, B. A.: The global atmospheric electric circuit and its effects on cloud microphysics, Rep. Prog. Phys., 71, 066801, doi:10.1088/0034-4885/71/6/066801, 2008.

Vali, G.: Nucleation terminology, B. Am. Meteorol. Soc., 66, 14261427, 1985.

Welti, A., Lüönd, F., Kanji, Z. A., Stetzer, O., and Lohmann, U.: Time dependence of immersion freezing: an experimental study on size selected kaolinite particles, Atmos. Chem. Phys., 12, 9893-9907, doi:10.5194/acp-12-9893-2012, 2012.

Wuerker, R. F., Shelton, H., and Langmuir, R. V.: Electrodynamic containment of charged particles, J. Appl. Phys., 30, 342-349, doi:10.1063/1.1735165, 1959. 